\title{
SIMULASI PRODUKSI ASAM LEVULINAT DAN NITROSELULOSA DARI TANDAN KOSONG KELAPA SAWIT
}

\section{THE SIMULATION OF LEVULINIC ACID AND NITROCELLULOSE PRODUCTION FROM PALM OIL EMPTY FRUIT BUNCHES}

\author{
Jabosar Ronggur Hamonangan Panjaitan \\ Program Studi Teknik Kimia, Institut Teknologi Sumatera, Lampung 35365, Indonesia \\ E-mail: jabosar.panjaitan@tse.itera.ac.id
}

Diterima : 06-07-2019

Direvisi : 29-05-2020

Disetujui : 08-06-2020

\begin{abstract}
ABSTRAK
Indonesia merupakan negara penghasil kelapa sawit terbesar di dunia. Tandan kosong kelapa sawit (TKKS) yang merupakan hasil samping industri kelapa sawit memiliki kandungan selulosa yang dapat dikonversi menjadi berbagai produk bernilai jual tinggi antara lain asam levulinat dan nitroselulosa. Asam levulinat diproduksi melalui reaksi hidrolisis selulosa sedangkan nitroselulosa dihasilkan menggunakan reaksi nitrasi selulosa. Penelitian ini bertujuan untuk meneliti simulasi produksi asam levulinat dan nitroselulosa dari TKKS berskala pabrik dengan kapasitas 100 ton TKKS/tahun menggunakan software SuperPro Designer 9.0. Hasil simulasi menunjukkan asam levulinat terbesar yang diperoleh pada penelitian ini adalah 5,633 ton/year pada suhu hidrolisis $170^{\circ} \mathrm{C}$. Sedangkan nitroselulosa terbesar yang diperoleh dari simulasi adalah 3,459 ton/tahun pada suhu hidrolsis $150^{\circ} \mathrm{C}$ dan suhu nitrasi $15^{\circ} \mathrm{C}$. Produk samping yang cukup banyak dihasilkan pada proses degradasi selulosa adalah humins yang juga mempengaruhi jumlah produksi asam levulinat dan nitroselulosa.
\end{abstract}

Kata kunci : asam levulinat, nitroselulosa, simulasi proses, skala industri, TKKS

\section{ABSTRACT}

Indonesia is the largest palm oil producer in the world. Oil palm empty fruit bunches (OPEFB), byproduct of the palm oil industry, contains cellulose which can be converted into a variety of high-value products such as levulinic acid and nitrocellulose. Levulinic acid can be produced through cellulose hydrolysis reaction while nitrocellulose can be produced using cellulose nitration reaction. In this research, simulation of levulinic acid and nitrocellulose production from OPEFB with 100 tons of OPEFB/year plant capacity using SuperPro Designer 9.0 was investigated. The simulation showed that the largest levulinic acid production from this study was 5.633 tons/year at $170^{\circ} \mathrm{C}$ hydrolysis temperature. On the other side, the largest nitrocellulose obtained from the simulation was 3.459 tons/year at $150^{\circ} \mathrm{C}$ hydrolysis temperature and $15^{\circ} \mathrm{C}$ nitration temperature. A significant byproduct from the cellulose degradation process was humins which affects the production of levulinic acid and nitrocellulose.

Keywords : OPEFB, levulinic acid, nitrocellulose, simulation process, industrial scale

\section{PENDAHULUAN}

7 ndonesia termasuk negara penghasil minyak kelapa sawit terbesar di dunia dengan kapasitas produksi 42,5 juta ton pada tahun 2019 (Index Mundi, 2020).

Tandan kosong kelapa sawit (TKKS) adalah salah satu limbah yang dihasilkan dari perkebunan kelapa sawit yaitu sekitar $22-23 \%$ dari total tandan buah segar (TBS) yang diolah yaitu sebesar 1,1 ton limbah untuk setiap 1 ton CPO yang diproduksi (Karina et al., 2008). Potensi TKKS berasal dari komposisi lignoselulosa yang ada antara lain kadar lignin 
sebesar 22,8\%, kadar selulosa-a sebesar 39,3\% dan kadar hemiselulosa sebesr 29,8\% (Gozan et al., 2018). TKKS sudah mulai dimanfaatkan untuk mengurangi dampak pencemaran lingkungan dan meningkatkan nilai ekonomisnya seperti dimanfaatkan sebagai biobriket (Maitah et al., 2016) dan biocomposite films (Zailuddin dan Husseinsyah, 2016). Akan tetapi, selulosa pada TKKS memiliki potensi untuk dapat dikonversi menjadi berbagai produk yang bernilai jual tinggi antara lain adalah asam levulinat dan nitroselulosa.

Asam levulinat dikenal sebagai platform chemical karena dapat memproduksi berbagai senyawa lainnya, seperti asam 5-bromolevulinat, asam valerik, MTHF, metil pirolidon, dan lain - lain (Girisuta et al., 2006). Potensi asam levulinat sebagai biofuel sangat besar dikarenakan asam levulinat dapat dikonversi menjadi $\gamma$-valerolactone (GVL), 2methyltetrahydrofuran dan levulinate esters dimana ketiga produk ini adalah bahan bakar alternatif penggati fosil fuel. Metode hidrolisis biomassa menggunakan katalis asam adalah salah satu proses yang dapat dilakukan untuk memproduksi asam levulinat. Secara berturut - turut fraksi selulosa yang ada pada biomassa akan terkonversi menjadi glukosa, glukosa akan terkonversi menjadi hydroxymethylfurfural (HMF) dan HMF akan terkonersi menjadi asam levulinat. Kebutuhan asam levulinat di dunia mencapai mencapai 2.606,2 ton pada tahun 2013 dan diperkirakan akan meningkat mencapai 3.841 ton pada tahun 2020 (Grandview Research, 2014).

Produk potensial lainnya yang dapat dihasilkan dari konversi selulosa adalah nitroselulosa. Nitroselulosa dapat diaplikasikan pada berbagai industri antara lain indutri plastik, cat, perekat dan bahan bakar roket (propelan). Nitroselulosa dihasilkan melalui reaksi nitrasi antara selulosa dan asam nitrat (Seta et al., 2014). Kebutuhan nitroselulosa diprediksi akan meningkat sebesar 6,1\% dari tahun 2018 hingga 2024 (Grandview Research, 2018).

Produksi asam levulinat dan nitroselulosa dari TKKS termasuk salah satu konsep dari biorefineri berbasis lignoselulosa. Biorefineri adalah sebuah konsep yang mengintegrasikan proses konversi biomassa dan peralatan untuk memproduksi berbagai bahan kimia dari biomassa (Moncada et al., 2016). Tiga kategori besar dalam klasifikasi biorefineri berdasarkan sifat kimia biomasa sebagai bahan bakunya yaitu biorefineri berbasis trigliserida, biorefineri berbasis gula dan starch, dan biorefineri berbasis lignoselulosa (Maity, 2015).

Penelitian untuk memproduksi asam levulinat dan nitroselulosa sebagai produk tunggal telah banyak dilakukan, tetapi belum ada penelitian yang meneliti produksi biorefineri asam levulinat dan nitroselulosa di dalam satu bagan proses produksi. Oleh sebab itu, pada penelitian ini akan diteliti simulasi produksi asam levulinat dan nitroselulosa dari TKKS skala pabrik dengan menggunakan software SuperPro Designer 9.0. Penelitian ini menjadi menarik karena asam levulinat dan nitroselulosa merupakan produk bioenergi yang potensial.

\section{METODE PENELITIAN Alat Simulasi}

Perhitungan produksi pabrik asam levulinat dan nitroselulosa dari TKKS dilakukan menggunakan software simulasi SuperPro Designer 9.0 (Academic Licence). Kapasitas pabrik pada proses produksi yang dipakai adalah sebesar 100 ton TKKS/tahun dengan komposisi TKKS yaitu 3\% ash, 35\% selulosa, 30\% hemiselulosa, 25\% lignin, dan $7 \%$ air. Proses produksi asam levulinat dan nitroselulosa terdiri atas proses hidrolisis biomassa untuk memproduksi asam levulinat yang dilanjutkan dengan proses nitrasi untuk memproduksi nitroselulosa. Data kinetika reaksi produksi asam levulinat diambil dari Gozan et al. (2018) dan data kinetika reaksi produksi nitroselulosa diambil dari Ronggur et al. (2012) sebagai data kinetika pada software simulasi SuperPro Designer 9.0. Proses pemisahan pada proses 
produksi asam levulinat dan nitroselulosa akan menggunakan berbagai metode seperti pencucian, klarifikasi, kondensasi dan destilasi dengan efisiensi pemisahan sebesar $80 \%$.

\section{Alur Proses Simulasi Produksi Asam Levulinat dan Nitroselulosa}

Pada bagian awal proses produksi TKKS diperkecil ukurannya menggunakan grinder, lalu dicampur dengan katalis asam sulfat dan kemudian masuk ke dalam reaktor hidrolisis untuk memproduksi asam levulinat pada kondisi reaksi sesuai penelitian Gozan et al. (2018) dengan berbagai suhu reaksi hidrolisis $\left(150,160\right.$ dan $\left.170^{\circ} \mathrm{C}\right)$. Produk dari proses hidrolisis masuk ke dalam tangki pemisahan 1 untuk memisahkan antara produk cair dan padatan. Produk cair akan masuk ke dalam kolom destilasi untuk memurnikan asam levulinat dari limbah katalis asam. Sedangkan produk padat dari proses hidrolisis yaitu residu selulosa akan digunakan sebagai bahan baku nitroselulosa yang terlebih dahulu dicuci pada washer 1 dan dicampur dengan asam penitrasi yaitu asam sulfat dan asam nitrat. Nitroselulosa diproduksi pada kondisi reaksi sesuai penelitian Ronggur et al. (2012) dengan variasi suhu 5, 10 dan $15^{\circ} \mathrm{C}$. Produk padatan hasil nitrasi lalu dipisah di tangki pemisahan 2 dan dicuci untuk memperoleh nitroselulosa dengan konsentrasi $72 \%$. Bagan proses produksi asam levulinat dan nitroselulosa dapat dilihat pada Gambar 1.

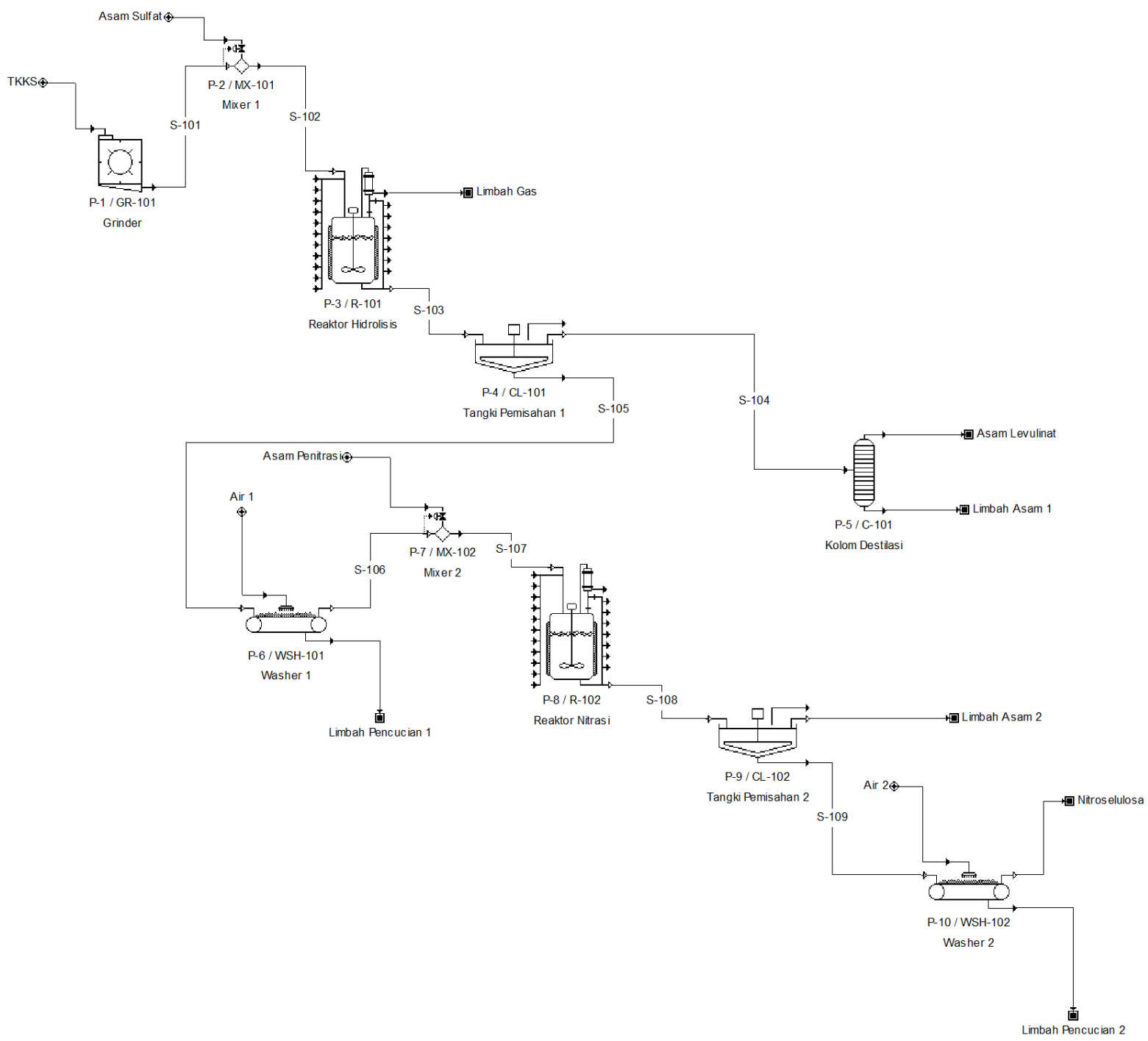

Gambar 1. Proses simulasi produksi asam levulinat dan nitroselulosa 
HASIL DAN PEMBAHASAN

Jumlah Produksi Asam Levulinat dan Nitroselulosa

Jumlah produksi dari asam levulinat dan nitrocellulose dapat dilihat pada Tabel 1.

Tabel 1. Jumlah produksi asam levulinat dan nitroselulosa

\begin{tabular}{ccccc}
\hline Kode Proses & $\begin{array}{c}\text { Suhu Hidrolisis } \\
\left({ }^{\circ} \mathrm{C}\right)\end{array}$ & $\begin{array}{c}\text { Suhu Nitrasi } \\
\left({ }^{\circ} \mathrm{C}\right)\end{array}$ & $\begin{array}{c}\text { Asam Levulinat } \\
\text { (ton/year) }\end{array}$ & $\begin{array}{c}\text { Nitroselulosa } \\
\text { (ton/year) }\end{array}$ \\
\hline A & & 5 & & 3,454 \\
B & 150 & 10 & 3,483 & 3,459 \\
C & & 15 & & 3,459 \\
D & & 5 & & 3,149 \\
E & 160 & 10 & 4,445 & 3,152 \\
F & & 15 & & 3,152 \\
G & & 5 & & 2,936 \\
H & 170 & 10 & 5,633 & 2,938 \\
I & & 15 & & 2,938 \\
\hline
\end{tabular}

Keterangan:

A: Simulasi produksi asam levulinat pada suhu $150^{\circ} \mathrm{C}$ dan produksi nitroselulosa pada suhu $5^{\circ} \mathrm{C}$

B: Simulasi produksi asam levulinat pada suhu $150^{\circ} \mathrm{C}$ dan produksi nitroselulosa pada suhu $10^{\circ} \mathrm{C}$

C: Simulasi produksi asam levulinat pada suhu $150^{\circ} \mathrm{C}$ dan produksi nitroselulosa pada suhu $15^{\circ} \mathrm{C}$

D: Simulasi produksi asam levulinat pada suhu $160^{\circ} \mathrm{C}$ dan produksi nitroselulosa pada suhu $5^{\circ} \mathrm{C}$

E: Simulasi produksi asam levulinat pada suhu $160^{\circ} \mathrm{C}$ dan produksi nitroselulosa pada suhu $10^{\circ} \mathrm{C}$

F: Simulasi produksi asam levulinat pada suhu $160^{\circ} \mathrm{C}$ dan produksi nitroselulosa pada suhu $15^{\circ} \mathrm{C}$

G: Simulasi produksi asam levulinat pada suhu $170^{\circ} \mathrm{C}$ dan produksi nitroselulosa pada suhu $5^{\circ} \mathrm{C}$

$\mathrm{H}$ : Simulasi produksi asam levulinat pada suhu $170^{\circ} \mathrm{C}$ dan produksi nitroselulosa pada suhu $10^{\circ} \mathrm{C}$

I: Simulasi produksi asam levulinat pada suhu $170^{\circ} \mathrm{C}$ dan produksi nitroselulosa pada suhu $15^{\circ} \mathrm{C}$

\section{Produksi Asam Levulinat}

Dari Tabel 1, dapat dilihat jumlah produksi asam levulinat dari berbagai variasi suhu reaksi hidrolisis. Suhu $170^{\circ} \mathrm{C}$ adalah suhu hidrolisis tertinggi yang dipakai untuk memproduksi asam levulinat dan menghasilkan asam levulinat tertinggi (kode proses $\mathrm{G}, \mathrm{H}$, dan I) dibanding suhu yang lain yaitu sebesar 5,633 ton/tahun. Sedangkan produksi asam levulinat pada suhu hidrolisis $160^{\circ} \mathrm{C}$ dan $150^{\circ} \mathrm{C}$ yaitu sebesar 4,445 ton/tahun dan 3,483 ton/tahun. $\mathrm{Hal}$ ini dapat disebabkan karena peningkatan suhu hidrolisis dalam rentang $150-230^{\circ} \mathrm{C}$ cenderung meningkatkan produksi asam levulinat (Rackemann dan Doherty, 2013).

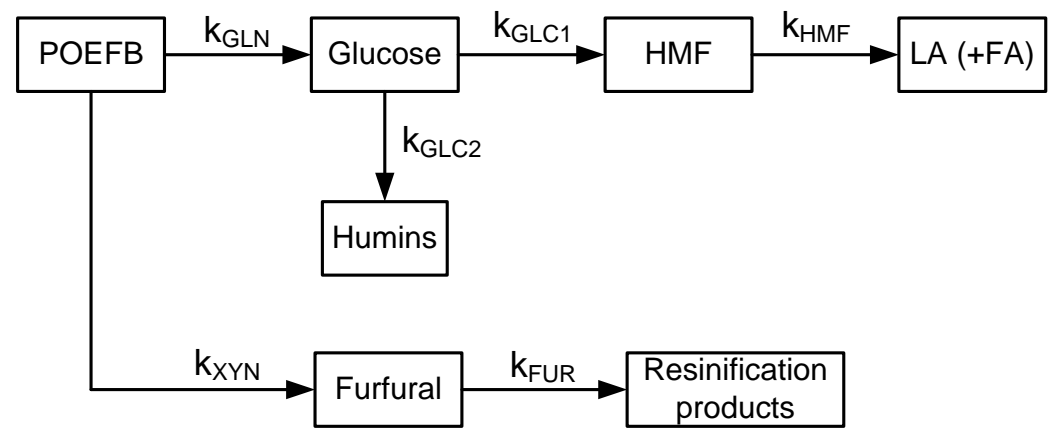

Gambar 2. Model kinetika asam levulinat (Sumber: Gozan et al., 2018) 
Yield Produksi asam levulinat dari TKKS dengan kapasitas 100 ton/tahun termasuk rendah. Hal ini disebabkan karena fraksi selulosa yang ada pada TKKS banyak diubah menjadi berbagai produk lainnya selain asam levulinat seperti glukosa, HMF, dan humins. Skema model dan data kinetika simultaneous produksi asam levulinat yang dipakai pada penelitian ini sesuai Gozan et al. (2018) dapat dilihat pada Gambar 2 dan model persamaan kinetika dapat dilihat dari persamaan (1) hingga (7).

$$
\begin{aligned}
& \frac{d C_{\text {POEFB }}}{d t}=-k_{\text {GLN }} \cdot C_{\text {POEFB }}-k_{\text {XLN }} \cdot C_{\text {POEFB }} \\
& \frac{d C_{\text {glucose }}}{d t}=k_{\text {GLN }} \cdot C_{\text {POEFB }}-k_{\text {GLC1 }} \cdot C_{\text {glueose }}-k_{\text {GLC2 }} \cdot C_{\text {glueose }} \\
& \frac{d C_{\text {HMF }}}{d t}=k_{\text {GLC2 }} \cdot C_{\text {glucose }}-k_{\text {HMF }} \cdot C_{\text {HMF }} \\
& \frac{d C_{\text {LA[T+FA) }}}{d t}=k_{\text {HMF }} \cdot C_{\text {HMF }} \\
& \frac{d C_{\text {HUM }}}{d t}=k_{\text {GLC2 }} \cdot C_{\text {glueose }} \\
& \frac{d C_{\text {furfural }}}{d t}=k_{\text {XYN }} \cdot C_{\text {POEFB }}-k_{\text {FUR }} \cdot C_{\text {furfural }} \\
& \frac{d C_{\text {RES }}}{d t}=k_{\text {FUR }} \cdot C_{\text {furfural }}
\end{aligned}
$$

Keterangan:

$\mathrm{C}_{\text {furfural }} \quad$ Konsentrasi furfural

$\mathrm{C}_{\mathrm{qlucose}} \quad$ Konsentrasi glukosa

$\mathrm{C}_{\mathrm{HMF}} \quad$ Konsentrasi 5 - hydroxylmethylfurfural (HMF)

$\mathrm{C}_{\text {HUM }} \quad$ Konsentrasi humins

$\mathrm{C}_{\mathrm{LA}(+\mathrm{FA}) \quad \text { Konsentrasi asam levulinat }}$

CPOEFB Konsentrasi fraksi selulosa dan hemiselulosa TKKS

$\mathrm{C}_{\mathrm{RES}} \quad$ Konsentrasi produk resinifikasi/produk degradasi furfural

HMF $\quad 5$ - hydroxylmethylfurfural

K KUR Konstanta reaksi degradasi furfural

$\mathrm{k}_{\mathrm{GLC1}} \quad$ Konstanta reaksi produksi HMF

$\mathrm{k}_{\mathrm{GLC} 2} \quad$ Konstanta reaksi produksi humins

$\mathrm{k}_{\mathrm{GLN}} \quad$ Konstanta reaksi degradasi selulosa

$\mathrm{k}_{\mathrm{HMF}} \quad$ Konstanta reaksi produksi asam levulinat

$\mathrm{k}_{\mathrm{XYN}} \quad$ Konstanta reaksi degradasi xilosa

Konstanta reaksi pada suhu $170^{\circ} \mathrm{C}$ sesuai persamaan (1) hingga (7) antara lain $\mathrm{k}_{\mathrm{GLN}}$ $\mathrm{k}_{\mathrm{GLC} 1}, \mathrm{k}_{\mathrm{GLC}}, \mathrm{k}_{\mathrm{HMF}}, \mathrm{k}_{\mathrm{XYN}}$, $\mathrm{k}_{\mathrm{FUR}}$ adalah sebesar 0,06328, 0,07026, 0,30007, 0,54766, 0,00753, 0,33419. Berdasarkan persamaan (4) dapat diketahui bahwa produksi asam levulinat bergantung dari HMF yang dihasilkan, dan produksi HMF bergantung dari konversi glukosa. Sesuai simulasi perhitungan yang telah dilakukan berdasarkan model konversi glukosa menjadi HMF dan humins dari persamaan (3) dan (5), dapat disimpulkan bahwa humins adalah produk yang paling banyak terbentuk dibandingkan HMF. Pada suhu 150, 160, dan 170 humins terbentuk sebesar 19,16; 18,36; dan 17,36 ton/tahun. Oleh sebab itu, glukosa cenderung terkonversi menjadi humins dibandingkan menjadi HMF yang menyebabkan produksi asam levulinat menjadi rendah. 


\section{Produksi Nitroselulosa}

Produksi nitroselulosa dari bagan proses sesuai Gambar 1 dilakukan didalam reaktor nitrasi. Berdasarkan Gambar 1 diketahui bahwa jumlah nitroselulosa yang dihasilkan sangat dipengaruhi oleh jumlah residu selulosa yang dihasilkan dari produksi asam levulinat. Semakin tinggi asam levulinat yang dihasilkan maka akan menghasilkan sedikit residu selulosa dan sedikit nitroselulosa. Nitroselulosa tertinggi yang dihasilkan dari penelitian ini sebesar 3,459 ton/tahun (kode proses $\mathrm{B}$ dan $\mathrm{C}$ ) pada suhu hidrolisis asam sebesar $150^{\circ} \mathrm{C}$ dan suhu nitrasi $10-15^{\circ} \mathrm{C}$.

Pengaruh suhu nitrasi pada produksi nitroselulosa dapat dilihat pada Tabel 1. Pada Tabel 1 reaksi nitrasi pada suhu $10-15^{\circ} \mathrm{C}$ menghasilkan yield nitroselulosa yang lebih tinggi dibandingkan suhu $5^{\circ} \mathrm{C}$. Hal ini dapat disebabkan karena reaksi nitrasi optimum pada suhu $10-15^{\circ} \mathrm{C}$.

Penjelasan suhu optimum nitrasi pada suhu $10-15^{\circ} \mathrm{C}$ dapat dilihat pada penelitian Ronggur et al. (2012) yang telah meneliti pengaruh suhu pada kinetika reaksi produksi nitroselulosa dari pelepah sawit dengan berbagai rentang suhu yaitu $5-10^{\circ} \mathrm{C}, 10-15^{\circ} \mathrm{C}$ dan $15-20^{\circ} \mathrm{C}$. Skema model dan data kinetika produksi nitroselulosa pada penelitian ini sesuai Ronggur et al. (2012) yang dapat dilihat pada Gambar 3 dan model persamaan kinetika yang dapat dilihat pada persamaan (8).

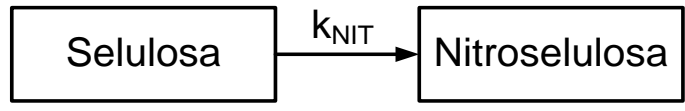

Gambar 3. Model kinetika nitroselulosa

$\frac{d C_{\text {NIT }}}{d t}=k_{\text {NIT }}, C_{\text {Selulosa }}$

Keterangan:

$\begin{array}{ll}\mathrm{C}_{\mathrm{NIT}} & \text { Konsentrasi nitroselulosa } \\ \mathrm{C}_{\text {Selulosa }} & \text { Konsentrasi selulosa } \\ \mathrm{k}_{\mathrm{NIT}} & \text { Konstanta reaksi produksi nitroselulosa }\end{array}$

Dari hasil penelitian Ronggur et al. (2012) diketahui bahwa suhu $10-15^{\circ} \mathrm{C}$ menghasilkan nilai konstanta reaksi $\left(\mathrm{k}_{\mathrm{NIT}}\right)$ yang paling besar dibandingkan rentang suhu nitrasi lainnya yaitu 0,109 . Nilai konstanta reaksi yang besar disebabkan oleh meningkatnya energi aktivasi dan nilai tumbukan antar molekul pereaksi sehingga meningkatkan nilai kecepatan reaksi. Oleh sebab itu, dapat disimpulkan bahwa suhu $10-15^{\circ} \mathrm{C}$ adalah suhu optimun untuk memproduksi nitroselulosa.

\section{KESIMPULAN}

Simulasi produksi asam levulinat dan nitroselulosa dari TKKS pada skala industri berkapasitas 100 ton TKKS/tahun telah dilakukan pada penelitian ini dengan menggunakan software SuperPro Designer 9.0. Berdasarkan hasil simulasi disimpulkan bahwa jumlah asam levulinat terbesar yang dihasilkan adalah 5,633 ton/year pada suhu hidrolisis $170^{\circ} \mathrm{C}$ dan jumlah nitroselulosa terbesar adalah 3,459 ton/tahun diperoleh pada suhu hidrolisis sebesar $150^{\circ} \mathrm{C}$ dan suhu nitrasi $15^{\circ} \mathrm{C}$. Humins merupakan salah satu produk samping yang cukup banyak dihasilkan pada proses degradasi selulosa yang juga mempengaruhi jumlah asam levulinat dan nitroselulosa yang dihasilkan. 


\section{UCAPAN TERIMA KASIH}

Penulis mengucapkan terima kasih kepada Institut Teknologi Sumatera karena telah memberikan hibah penelitian (No:B/328/IT9.C1/PT.01.03/2019) melalui "Hibah Penelitian ITERA SMART 2019".

\section{DAFTAR PUSTAKA}

Girisuta, B., P.B.M. Janssen, dan H.J. Heeres. 2006. Green Chemicals - A Kinetic Study on The Conversion of Glucose to Levulininc Acid. Chemical Engineering Research and Design 84(5): 339 - 349.

Gozan, M., J.R.H. Panjaitan, D. Tristantini, R. Alamsyah, dan Y.J. Yoo. 2018. Evaluation of separate and simultaneous kinetic parameters for levulinic acid and furfural production from pretreated palm oil empty fruit bunches. International Journal of Chemical Engineering 1920180: 1 - 12.

Grand View Research. 2014. Global Levulininc Acid Market Expected to Reach 3,820 Tons by 2020. http://www.grandviewresearch.com. 3 November 2015 (15:00).

Grand View Research. 2018. Nitrocellulose market size, share \& trends analysis report by application (printing inks, automotive paints, wood coatings, leather finishes, nail varnishes), by region, and segment forecasts, 2018-2024. http://www.grandviewresearch.com. 10 Februari 2019 (10:00).

Index Mundi. 2020. Indonesia Palm Oil Production by Year. https://www.indexmundi.com/agriculture. 17 April 2020 (08:35).

Karina, M., H. Onggo, A.H.D Abdullah, dan A. Syampuradi. 2008. Effects of oil palm empty fruit bunch fiber on the physical and mechanical properties of fiber glass reinforced polyester resin. Journal of Biological Science 8(1): 101-106.

Maitah, M., P. Prochazka, A. Pachmann, K. Srel, dan H. Rezbova. 2016. Economics of Palm Oli Empty Fruit Bunches Bio Briquettes In Indonesia. International Journal of Energy Economics and Policy. 6(1): 35 - 38.

Maity, S.K. 2015. Opportunities, recent trends and challenges of integrated biorefinery: Part 1. Renewable and Sustainable Energy Reviews. 43: 1427 - 1445.

Moncada, J., C.A. Cardona, J.C. Higuita, J.J. Velez, dan F.E.L. Suarez. 2016. Wood Residue (Pinus patula bark) as an alternative feedstock for producing ethanol and furfural in Colombia: experimental, techno-economic and environmental assessments. Chemical Engineering Science. 140: 309 - 318.

Rackemann, D.W., dan W.O.S. Doherty. 2011. The Coversion of Lignocellulosics to Levulinic Acid. Biofuels, Bioproducts and Biorefining 5(2): $115-126$.

Ronggur, J. 2012. Kinetika Reaksi Proses Nitrasi Limbah Pelepah Sawit. Skripsi. Universitas Riau. Pekanbaru.

Seta, F.T., S. Sugesty, dan T. Kardiansyah. 2014. Pembuatan nitroselulosa dari berbagai pulp larut komersial sebagai bahan baku propelan. Jurnal Selulosa 4: 97-106.

Zailuddin, N.L.I., dan S. Husseinsyah. 2016. Tensile Properties and Morphology of Oil Palm Empty Fruit Bunch Regenerated Cellulose Biocomposite Films. Procedia Chemistry. 19: $366-372$. 